\title{
X. Remarks on Sir J. W. Lubbock's "Theory of Heat and Vapours."
}

\author{
James Ivory K.H. M.A. Hon. M.R.I.A.
}

To cite this article: James Ivory K.H. M.A. Hon. M.R.I.A. (1842) X. Remarks on Sir J. W. Lubbock's "Theory of Heat and Vapours.", Philosophical Magazine Series 3, 20:128, 46-49, DOI: $10.1080 / 14786444208650512$

To link to this article: http://dx.doi.org/10.1080/14786444208650512

册 Published online: 01 Jun 2009.

Submit your article to this journal $\sqsubset \pi$

Џll Article views: 2

Q View related articles $\square$ 
I have tried similar experiments with water placed in the rays of the sun, and on all occasions the evaporation has been greatest from the non-insulated vessel. There is a difficulty in obtaining correct calculations from the above experiments, as it is scarcely possible to keep up complete insulation from electricity; and the vessel of water must have its proportion of electricity when placed in an insulating situation, which will assist the evaporation for some time; but I believe if complete insulation could be obtained, and a vessel left without any electricity, that no evaporation would go on at moderate temperatures, and that evaporation at low temperature is owing to the extreme lightness, or rather no weight of electricity, buoying up the particles of water when expanded by heat.
Oxford, Oct. 8, 1841.
I am, Gentlemen, yours, \&c.
G. A. Rowell.

X. Remarks on Sir J. W. Lubbock's "Theory of Heat and Vapours." By James Ivonx, K.H., M.A., Hon. M.R.I.A., Instit. Reg. Sic. Paris, et Reg. Sc. Götting. Corresn., and late a Fellow of the Royal Society of London*.

$T^{H}$ HE Theory of Heat and Vapours, published some time ago by Sir J. W. Lubbock, and reprinted in this Journal, [S. 3. vols. xvi. xvii.], requires some observations from me. It is not intended to examine minutely the whole tract, but only to make some brief remarks on the two last sections which treat of the atmosphere and the atmospheric refractions. The temperature, the density, and the pressure of a mass of air being represented by $\theta, \rho, p$, the author assumes this equation,

$$
\mathbf{V}=\mathbf{C}+\mathbf{D}(1+\alpha \theta)
$$

in which $\mathrm{V}$ stands for the absolute heat, that is, for the sum of the sensible and latent heats, and $C$ and $D$ are constants. The author next adopts another equation, first given by Laplace, viz.

$$
\mathrm{V}=\mathrm{A}+\beta \frac{p^{\frac{1}{\gamma}}}{p^{2}}
$$

$A, \beta$ and $\gamma$ being constants. By equating the two values of $\mathrm{V}$, we obtain

$$
\mathrm{C}+\mathrm{D}(1+\alpha \theta)=\mathrm{A}+\beta \frac{p^{\frac{1}{\gamma}}}{\rho},
$$

which is the fundamental equation of the Theory of Heat

* Communicated by the Author. 
and Vapours*. But in the case of atmospheric air, we likewise have this well-known equation,

$$
p=k \rho(1+a \theta) \text {; }
$$

and it will easily be seen that this latter equation is inconsistent with the former one; for from it we obtain $\frac{1}{\rho}=\frac{k(1+\alpha \theta)}{p}$, and this value being substituted in the other equation, we get

$$
\frac{\mathbf{C}-\mathbf{A}}{k \mathbf{B}}=(1+\alpha \theta) \cdot\left(\begin{array}{c}
\mathrm{j}-\gamma \\
\left.p \gamma-\frac{\mathrm{D}}{k \mathrm{~B}}\right)
\end{array}\right.
$$

which would prove that the pressure is determined when the temperature is given, a property that certainly is not verified in the atmosphere. It is most evident, that, in atmospheric air, there can be no general relation between $\theta, \rho, p$, except the law of Mariotte.

As the fundamental equation of the Theory of Vapours is inadmissible in the case of atmospheric air, we might at once reject all the deductions from it: but it may be worth while to add a few words in order to throw some light on the calculations which follow. Let $\theta^{\prime}, p^{\prime}, p^{\prime}$, and $\theta^{\prime \prime}, p^{\prime \prime}, p^{\prime \prime}$ be other values of $\theta, \rho, p$; and put $\beta=\frac{1-\gamma}{\gamma}, \mathrm{E}=\frac{\mathrm{D}}{k \mathbf{B}}$; then we get from the last equation,

and hence

$$
\begin{aligned}
& \frac{\mathbf{C}-\mathbf{A}}{k \mathbf{B}}=(1+\alpha \theta) \cdot\left(p^{\beta}-\mathbf{E}\right) \\
& \frac{\mathbf{C}-\mathbf{A}}{k \mathbf{B}}=\left(1+\alpha \theta^{\prime}\right) \cdot\left(p^{\prime \beta}-\mathbf{E}\right) \\
& \frac{\mathbf{C}-\mathbf{A}}{k \mathbf{B}}=\left(1+\alpha \theta^{\prime \prime}\right) \cdot\left(p^{\prime \prime \beta}-\mathbf{E}\right):
\end{aligned}
$$

$$
\begin{aligned}
& p^{\prime \beta}=\frac{1+\alpha \theta}{1+\alpha \theta^{\prime}} \times\left(p^{\beta}-\mathrm{E}\right)+\mathrm{E} \\
& p^{\prime \prime \beta}=\frac{1+\alpha \theta}{1+\alpha \theta^{\prime \prime}} \times\left(p^{\beta}-\mathrm{E}\right)+\mathrm{E},
\end{aligned}
$$

equations which cannot obtain generally in the atmosphere; because, as has been said, the three equations from which they are derived are not properties of atmospheric air. But if we set aside the theoretical views of Sir J. W. Lubbock, and understand each of the two equations as merely expressing a relation between the quantities it contains, the two constants, $\beta$ and $E$, will be determined when $\theta, p, \theta^{\prime}, p^{\prime}, \theta^{\prime \prime}, p^{\prime \prime}$ are found by means of three separate observations. Sir J. W.

$$
\text { * Theor., p. } 2 .
$$


48 On Sir J. W. Lubbock's Theory of Heat and Vapours.

Lubbock makes choice of three elevations observed by GayLussac in his aëronautic ascent from Paris; and he finds

$$
\gamma=1 \cdot 4910, \mathrm{E}=-1 \cdot 1618
$$

which he changes to

$$
\gamma=1 \cdot 5, \mathrm{E}=-1 \cdot 192 .
$$

With these constants, the two equations will, no doubt, verify the observed values of $p^{\prime}, p^{\prime \prime}$; but, as $\gamma$ and $\mathrm{E}$ have been deduced from three particular observations, there is no evidence to prove that, with any other three assumed observations, the constants will, in every case, retain the same values. Thus if $\theta^{\prime \prime \prime}$ and $p^{\prime \prime \prime}$ be new observed values, the equation

$$
p^{\prime \prime \prime \beta}=\frac{1+\alpha \theta}{1+\alpha \theta^{\prime}} \cdot\left(p^{\beta}-\mathrm{E}\right)+\mathrm{E}
$$

will not hold with the same values of $\gamma$ and $E$, as before.

Such calculations retard knowledge by erroneous views. The author applies his equations to barometrical measurements, and to the refractions; but his processes have no foundation whatever in the constitution of the atmosphere.

We can hardly help noticing how fruitless it must be to attempt solving physical problems by means of algebraic equations containing many arbitrary constants. In such problems the constants are improperly called arbitrary : they are indeterminate, and must be found by observation or experiment; but as they are mixed with the other quantities in the equations of the problem, they are independent on the will of the calculator. In the Theory of the Moon, the coefficient of the cosine of the mean anomaly in the reciprocal of the radius vector is one of the constants, which must be found by comparing the theoretical with the observed place of the moon. Now this constant varies with the disturbing force; and if any one, not attending to this circumstance, should be rash enough to fix its value by an arbitrary definition, many errors would thereby be introduced in the expression of the moon's motion.

In Sir Humphry Davy's Chemical Philosophy this passage occurs at p. 233:- " Air analysed in different quarters of the globe, in cities and in the country, on sea and land, has been found not perceptibly different in composition : the accurate proportions of oxygen and azote are 21 and 79." Here it must be understood that air is unmixed with aqueous vapour or carbonic acid gas. The experiments of MM. Dumas and Boussingault, recorded in the Comptes Ren$d u s$, June 7,1841 , confirm the words of the illustrious chemist. It thus appears that the atmosphere, at different 
places, consists, at all elevations, of the same two gases mixed in the same proportion. This property is equivalent to the law of Mariotte, which is a consequence of it; for the elastic force in all gases being proportional to the product of the temperature, density, and a constant which varies with the nature of the gas, the law of Mariotte will hold good in a mixture of two gases, when the volumes of the constituent parts preserve constantly the same proportion. One general law of the constitution of the atmosphere is thus obtained; to which must be added the usual equation of equilibrium. By combining these two properties we deduce a relation between the temperature and pressure at the earth's surface, and the temperature, pressure, and height, at any elevation. But another property is still wanting to complete the development of the constitution of the atmosphere. We must know the law of the decrease of heat in ascending; of which we are at present entirely ignorant, except the rate of decrease at the earth's surface expressed by the height required to depress the thermometer one degree. Now, from this imperfect element $I$ have already deduced the barometrical formula in its most improved form; and have computed a table of refractions agreeing with the observed quantities as far as they have been ascertained. My object in the above detail of the chief steps of my investigation, is to enable the unprejudiced inquirer to judge of its soundness and originality.

\section{Proceedings of Learned Societies.}

GEOLOGICAL SOCIETY.

[Continued from vol. xix. p. 547.]

June 2, " $\mathrm{N}$ the Faluns of the Loire, and a comparison of their 1841. ' Fossils with those of the newer Tertiary Strata in the Cotentin, and on the relative age of the Faluns and Crag of Suffolk," by Charles Lyell, Esq., V.P.G.S.

In a paper "On the Crag of Norfolk and Suffolk," read in 1839*, Mr. Lyell stated, that when M. Desnoyers assigned in 1825 a contemporaneous origin to the Crag and the Faluns of Touraine, he dissented from the conclusion; first, because the per-centage of recent species then assigned to the crag, including the Norwich beds, was greater than that ascribed by M. Deshayes to the shells of Touraine; 2ndly, because almost all the fossils in each locality were of distinct species, though only 300 miles apart; and 3rdly, because the fauna of the Suffolk crag had a northern, and that of Touraine an almost tropical aspect, notwithstanding the geographical proximity of the

* Proceedings, vol. iii. p. 171. 1839 [Phil. Mag., Third Series, vol, xv. p. 407, 411 - ED.].

Phil. Mag. S. 3. Vol, 20. No. 128. Jan. 1842. E 